\title{
Correlation between Age, Emergency Department Length of Stay and Hospital Admission Rate in Emergency Department Patients Aged $\geq 70$ Years
}

\author{
Roland Biber ${ }^{a, d}$ Hermann Josef Bail ${ }^{a}$ Cornel Sieber ${ }^{c, d}$ Peter Weis ${ }^{b}$ \\ Michael Christ ${ }^{\mathrm{b}}$ Katrin Singler ${ }^{\mathrm{c}, \mathrm{d}}$ \\ Departments of ${ }^{\mathrm{a}}$ Trauma and Orthopaedic Surgery, ${ }^{\mathrm{b}}$ Emergency and Critical Care Medicine, and ${ }^{\mathrm{C}}$ Geriatrics, \\ Klinikum Nürnberg, and ${ }^{\mathrm{d} I n s t i t u t e}$ for Biomedicine of Aging, Friedrich Alexander University, Nuremberg, Germany
}

\section{Key Words}

Emergency department $\cdot$ Geriatric patient $\cdot$ Length of stay •

Admission rate

\begin{abstract}
Background: Interdisciplinary emergency departments (EDs) are confronted with trauma and nontrauma patients of any age group. Length of stay (LOS) and admission rates reflect both disease complexity and severity. Objective: To evaluate LOS and admission rates in different age groups according to traumatic and nontraumatic etiologies. Patients and Methods: During May 2011 a total of 4,653 adult patients (defined as $\geq 18$ years old) seen in the ED of our municipal hospital were evaluated for their primary problem, Emergency Severity Index, LOS and admission rate. 1,841 trauma patients (mean age: 51.9 years; SD 22.5 years) and 2,812 nontrauma patients (mean age: 60.0 years; SD 20.4 years) were included. Results: Median LOS in the ED was 1:41 h (trauma) and 1:52 $\mathrm{h}$ (nontrauma). Trauma patients aged $\geq 70$ years spent more time in the ED than nontrauma patients of this age group (patients aged $\geq 70$ years median: $2: 08$ vs. 1:56 h; $p<0.0001)$. However, no significant difference was found in patients aged $<70$ years (1:33 vs. 1:48 $h ; p=0.64$ ). Comparing older with younger patients, median LOS within the ED was about 8 min longer in nontrauma patients aged $\geq 70$ years $(p=0.22)$ and about 35 min longer in trauma patients aged
\end{abstract}

\section{KARGER}

Fax +4161306 1234

E-Mail karger@karger.ch

www.karger.com (c) 2012 S. Karger AG, Basel

0304-324X/13/0591-0017\$38.00/0

Accessible online at:

www.karger.com/ger $\geq 70$ years $(p<0.00001)$. Conclusions: The correlation between age and LOS is stronger for trauma patients, which might indicate a special need for geriatric expertise in elderly trauma ED patients. Thus an interdisciplinary approach including surgical and geriatric expertise may be advantageous.

Copyright $\odot 2012$ S. Karger AG, Basel

\section{Background}

Emergency departments (ED) play a crucial role in the management of hospital patients. Besides the provision of emergency treatment and a 24-hour access to primary medical care, EDs work as a gate-keeper giving access to acute care as well as to long-term health care services. Triage and rapid diagnosis of the underlying disease or trauma as well as rapid treatment initiation and patient disposition belong to the main responsibilities of the emergency physician [1].

The implementation of independent central EDs has led to greater professionalism in emergency care [2], and thus the number of patients treated in EDs worldwide is steadily growing. Surveys have shown a rise in German ED visits of 4\% in 2006 and 8\% in 2007, with a total of around 12 million ED visits in 2007 [2]. Length of stay (LOS) in the ED depends on several factors described in 
the literature. Crucial factors for an increase in LOS in EDs are hospital occupancy, patient acuity, triage interventions and staffing [3].

Both professionalization of emergency medicine and the increasing number of elderly patients lead to increased ED usage. Several studies showed an overrepresentation of elderly patients in EDs compared to the proportion of elderly people in the general population [4]. Elderly patients are known to have distinct patterns of presentation and emergency care needs. They are more likely to enter the ED via the Emergency Medical Service, are more often referred to the ED by their primary care physician, have a higher proportion of urgent visits and are more likely to be admitted to hospital [4]. Atypical disease presentation, comorbidities, polypharmacy, cognitive and functional decline aggravate rapid triage and diagnosis in this age group [5]. A recent study confirmed patients aged $>65$ years to be at risk for undertriage [6].

Most of the elderly ED patients are nontrauma patients, but a large number of ED visits in this age group are due to musculoskeletal problems, which might be caused by either major traumatic injuries or a combination of minor trauma and degenerative disease. The primary goal of this study was to compare time consumption and admission rates between trauma and nontrauma patients of different age groups.

\section{Objective of the Study}

The objective of this study was to analyze the correlations between age, patient acuity, LOS and admission rates in elderly ED patients in order to evaluate the needed resources and treatment complexity in this patient group.

\section{Patients and Methods}

We retrospectively analyzed 4,653 consecutive patients aged $\geq 18$ years seen in our ED. The patients were evaluated for age, sex, Emergency Severity Index (ESI) [7] and LOS within the ED. Moreover, it was reported whether the patients needed to be admitted for inpatient hospital treatment. The institutional ethics review board was informed and issued a certificate of nonobjection for this retrospective study.

The study was conducted in an urban university affiliated hospital. The municipal institution serves a city population of 500,000 and an urban hinterland of 2,500,000 people. Besides our institution, there is one more hospital providing maximum medical care located in the area. There are no selection criteria in our institution: any patient with an acute medical or surgical problem can be seen at any time.
The ED has 10 treatment rooms and 2 resuscitation rooms; 5 ventilators are located within the ED. Ultrasound, X-ray, CT, MRI as well as all relevant laboratory examinations are available $24 \mathrm{~h}$ a day. At least 2 emergency physicians, 2 trauma surgeons, 1 neurologist and 1 radiologist are continuously on duty. During daytime, of internal medicine consultants and surgeons are also available. All members of the nursing staff were trained for at least 3 years.

Classification of patients as 'trauma' or 'nontrauma' patients was done by the nursing staff using standardized algorithms. LOS was defined as time from entry to the ED until discharge, transfer to another ward, or death. LOS was measured in minutes by the medical information system. For evaluation of patient acuity, the ESI, which had been routinely documented by trained ED nursing staff, was analyzed.

\section{Statistical Analysis}

Continuous variables are presented as means \pm standard deviations (SDs) or medians and interquartile ranges (IQRs), and categorical variables as numbers and percentages. The $\chi^{2}$ test was used for analysis of proportions. As LOS in the ED appeared not to be normally distributed, the Mann-Whitney U test was used to test the hypothesis that LOS of trauma patients aged $<70$ years is longer than that of nontrauma patients of the same age group. Comparison of ESI classifications was also performed using this nonparametric test. Correlation coefficients were calculated using Kendall's $\tau$. All confidence intervals (CIs) in this article are $95 \%$. $\mathrm{p} \leq 0.05$ was considered to be statistically significant. Data were processed using IBM $^{\circledR}$ SPSS $^{\circledR}$ version 19.0.0.

\section{Results}

In total, 4,653 patients visited the ED during the study period. 1,841 patients $(39.6 \%$; mean age: 51.9 years; SD 22.5 years) were trauma patients whereas 2,812 (60.4\%; mean age: 60.0 years; SD 20.4 years) had been categorized as nontrauma patients. Whereas nontrauma patients displayed a median ESI of 2, the median ESI of trauma patients was 4 (p<0.0001). 1,691 (36.3\%) patients were aged $\geq 70$ years, of whom 544 (32.2\%) were trauma patients (table 1).

Overall median LOS in the ED was 1:47 h (IQR: 0: 35-2:55). Among the 4,653 patients there were 2,339 males (mean age 54.0 years; SD 20.5 years) and 2,314 females (mean age 59.6 years; SD 22.3 years). The median LOS did not differ significantly between males and females (1:42 vs. $1: 52 \mathrm{~h} ; \mathrm{p}=0.415)$ (table 2).

2,053 patients $(44.1 \%)$ received ambulatory treatment whereas 2,600 (55.9\%) became inpatients. The median LOS in the ED was 8 min shorter for ambulatory patients (1:43 vs. $1: 51 \mathrm{~h} ; \mathrm{p}=0.269$ ). Acuity according to ESI classification was significantly higher in patients who had to be admitted to hospital (median ESI 2 in inpatients vs. ESI 4 in ambulatory patients; $\mathrm{p}<0.0001$ ). The rate of ad- 
Table 1. LOS, admission rates, median ESI and primary causes of ED visits among patients aged $<70$ and $\geq 70$ years

\begin{tabular}{|c|c|c|c|}
\hline & $<70$ years & $\geq 70$ years & All age groups \\
\hline \multicolumn{4}{|l|}{ Gender } \\
\hline Male & $1,650(55.7 \%)$ & $689(40.7 \%)$ & $2,339(50.3 \%)$ \\
\hline Female & $1,312(44.3 \%)$ & $1,002(59.3 \%)$ & $2,314(49.7 \%)$ \\
\hline Median LOS & $1: 40$ & $2: 00$ & $1: 47$ \\
\hline IQR & $0: 35-2: 46$ & $0: 37-3: 10$ & $0: 35-2: 55$ \\
\hline Admission rate & $42.2 \%$ & $79.8 \%$ & $55.9 \%$ \\
\hline CI & $40.5-44.0 \%$ & $77.9-81.7 \%$ & $54.5-57.3 \%$ \\
\hline Median ESI & 3 & 2 & 3 \\
\hline \multicolumn{4}{|l|}{ Primary problem } \\
\hline Medical $^{1}$ & $928(31.3 \%)$ & $757(44.8 \%)$ & $1,685(36.2 \%)$ \\
\hline Neurologic ${ }^{2}$ & $520(17.6 \%)$ & $298(17.6 \%)$ & $818(17.6 \%)$ \\
\hline Orthopaedic ${ }^{3}$ & $1,077(36.4 \%)$ & $434(25.7 \%)$ & $1,511(32.5 \%)$ \\
\hline Reconstructive surgical $^{4}$ & $86(2.9 \%)$ & $14(0.8 \%)$ & $100(2.1 \%)$ \\
\hline Maxillofacial surgical $^{5}$ & $69(2.3 \%)$ & $27(1.6 \%)$ & $96(2.1 \%)$ \\
\hline Neurosurgical $^{6}$ & $46(1.6 \%)$ & $31(1.8 \%)$ & $77(1.7 \%)$ \\
\hline Vascular surgical $^{7}$ & $19(0.6 \%)$ & $37(2.2 \%)$ & $56(1.2 \%)$ \\
\hline Others & $217(7.3 \%)$ & $93(5.5 \%)$ & $310(6.6 \%)$ \\
\hline Total & $2,962(100 \%)$ & $1,691(100 \%)$ & $4,653(100 \%)$ \\
\hline
\end{tabular}

mission for inpatient treatment was $69.4 \%$ in nontrauma patients versus $35.3 \%$ in trauma patients $(\mathrm{p}<0.00001)$. In nontrauma patients, this rate was $56.6 \%$ for patients aged $<70$ years, and $89.5 \%$ for patients aged $\geq 70$ years. On the other hand, $25.3 \%$ of trauma patients aged $<70$ years versus $60.8 \%$ of those aged $\geq 70$ years needed inpatient treatment. For patients aged $<70$ years these figures give a relative risk of 2.2 for inpatient admission when comparing nontrauma and trauma patients. In patients aged $\geq 70$ years, this relative risk is reduced to 1.5. However, there was a significant rank correlation between age and admission rate for both trauma and nontrauma patients $(\mathrm{p}<0.0001)$, which was nearly equal in strength $(\tau-\mathrm{b} 0.31$ vs. 0.34).

Analyzing the median LOS in relation to patient age (fig. 1), trauma patients aged $\geq 70$ years spent significantly more time in the ED (2:08 vs. $1: 56 \mathrm{~h} ; \mathrm{p}<0.0001)$. In patients aged $<70$ years, the median LOS was longer in nontrauma patients; however, the difference was not significant ( $1: 33$ vs. $1: 48 \mathrm{~h} ; \mathrm{p}=0.656$ ).

The median LOS of nontrauma patients aged $\geq 70$ years was not significantly different from that of younger

Age, Emergency Department Length of

Stay and Hospital Admission Rate nontrauma patients ( $1: 56$ vs. $1: 48 \mathrm{~h} ; \mathrm{p}=0.209)$. In trauma patients, however, LOS was significantly longer in patients aged $\geq 70$ years $(2: 08$ vs. $1: 33 \mathrm{~h} ; \mathrm{p}<0.00001)$. The rank correlation between patient age and LOS was not significant for nontrauma patients $(\tau-\mathrm{b}=0.01, \mathrm{p}=0.468)$; for trauma patients, it was significant, however $(\tau-b=0.1$, $\mathrm{p}<0.0001)$.

In patients aged $\geq 70$, the median ESI turned out to be significantly lower in nontrauma patients (ESI 2 for nontrauma versus ESI 3 for trauma patients; $p<0.0001)$. On the other hand, patients aged $<70$ years displayed a median ESI of 2 in nontrauma versus a median ESI of 4 in trauma patients $(\mathrm{p}<0.0001)$. A detailed overview about ESI classification in trauma and nontrauma patients of different age groups is shown in figure 2.

\section{Discussion}

In our study, nontrauma patients aged $\geq 70$ years had shorter LOS compared to trauma patients of the same age group. It is widely accepted that shorter LOS in the ED 
Table 2. Patient numbers, ED LOS and admission rates observed in the respective age groups

\begin{tabular}{|c|c|c|c|c|c|c|c|c|c|c|}
\hline \multirow[t]{2}{*}{ Age, years } & \multicolumn{2}{|l|}{$\mathrm{n}$ (male/female) } & \multicolumn{2}{|c|}{$\begin{array}{l}\text { Median LOS } \\
\text { h:min }\end{array}$} & \multicolumn{2}{|c|}{$\begin{array}{l}\text { LOS IQR range, } \\
\text { h:min }\end{array}$} & \multicolumn{2}{|c|}{ Admission rate, $\%$} & \multicolumn{2}{|c|}{$\begin{array}{l}\text { Admission rate } \\
95 \% \text { CI }\end{array}$} \\
\hline & trauma & nontrauma & trauma & nontrauma & trauma & nontrauma & trauma & nontrauma & trauma & nontrauma \\
\hline \multirow[t]{2}{*}{$21-30$} & \multicolumn{2}{|c|}{$573(323 / 250)$} & \multicolumn{2}{|c|}{$1: 36$} & \multicolumn{2}{|c|}{$0: 41-2: 32$} & \multicolumn{2}{|c|}{23} & \multicolumn{2}{|c|}{$19-26$} \\
\hline & $332(217 / 115)$ & $241(106 / 135)$ & $1: 28$ & $1: 54$ & $0: 47-2: 19$ & $0: 30-3: 02$ & 15 & 33 & $11-19$ & $27-39$ \\
\hline \multirow[t]{2}{*}{$31-40$} & \multicolumn{2}{|c|}{$503(268 / 235)$} & \multicolumn{2}{|c|}{$1: 41$} & \multicolumn{2}{|c|}{$0: 40-2: 44$} & \multicolumn{2}{|c|}{27} & \multicolumn{2}{|c|}{$23-31$} \\
\hline & $251(139 / 112)$ & $252(129 / 123)$ & $1: 38$ & $1: 46$ & $0: 55-2: 35$ & $0: 30-3: 00$ & 18 & 36 & $13-23$ & $30-42$ \\
\hline $41-50$ & $254(174 / 80)$ & $342(184 / 158)$ & $1: 31$ & $1: 41$ & $0: 54-2: 34$ & $0: 30-3: 12$ & 20 & 59 & $15-25$ & $54-65$ \\
\hline \multirow[t]{2}{*}{$51-60$} & \multicolumn{2}{|c|}{$574(316 / 258)$} & \multicolumn{2}{|c|}{$1: 45$} & \multicolumn{2}{|c|}{$0: 31-2: 53$} & \multicolumn{2}{|c|}{59} & \multicolumn{2}{|c|}{$55-63$} \\
\hline & $211(121 / 90)$ & $363(195 / 168)$ & $1: 30$ & $1: 53$ & $0: 44-2: 34$ & : 0:30-3:05 & 41 & 69 & $34-47$ & $65-74$ \\
\hline \multirow[t]{2}{*}{$61-70$} & \multicolumn{2}{|c|}{$611(334 / 277)$} & \multicolumn{2}{|c|}{$1: 45$} & \multicolumn{2}{|c|}{$0: 32-2: 58$} & & & & \\
\hline & $173(96 / 77)$ & $438(238 / 200)$ & $1: 41$ & $1: 45$ & $0: 55-2: 31$ & $0: 30-3: 15$ & 50 & 72 & $43-58$ & $68-77$ \\
\hline $71-80$ & $844(3$ & $0 / 454)$ & & & $0: 37$ & $-3: 11$ & & & & \\
\hline & $40(14 / 26)$ & $58(17 / 41)$ & $2: 36$ & $1: 40$ & $1: 22-3: 31$ & 0:29-3:08 & 50 & 91 & $34-66$ & $84-99$ \\
\hline all ages $(\geq 18)$ & $4,653(2$ & $339 / 2,314)$ & & & $0: 35$ & $-2: 55$ & & & & \\
\hline & $1,841(996 / 845)$ & $2,812(1,343 / 1,469)$ & $1: 41$ & $1: 52$ & $0: 55-2: 40$ & $0: 30-3: 07$ & 35 & 69 & $33-37$ & $67-71$ \\
\hline
\end{tabular}

Centered figures represent total patient numbers, total median LOS, total LOS IQR, total admission rate and admission rate CI, respectively.

correlate well with better outcomes after myocardial infarction, stroke, polytrauma, sepsis, and other acute health problems [8-11]. This might be especially true for elderly patients, who are at an increased risk because of their comorbid conditions, cognitive and functional decline and polypharmacy. Thus LOS in the ED may be regarded as an aspect of quality within an institution.

Different LOS may reflect different amounts of resources needed for patient care. Elderly patients need more ED resources [12], so a longer LOS in the ED should be expected in that group.

In our study, this applies especially to trauma patients aged $\geq 70$ years. An increase in resource consumption among elderly ED patients is confirmed by the lower ESIs in our study. LOS, however, did not significantly differ between nontrauma patients aged $<70$ and $\geq 70$ years. Only trauma patients aged $\geq 70$ years had a significantly increased LOS compared to patients aged $<70$ years.

The admission rates of different patient groups may also be regarded as an indicator of disease severity. In both trauma and nontrauma patients, admission rates were increasing with age. Compared to younger patients, the relative risk of admission was increased by factor 1.6 in geriatric nontrauma patients and by a factor of 2.3 in geriatric trauma patients. Despite this difference, the cor- relation between age and admission rate was nearly equal in trauma and nontrauma patients.

Our findings suggest that trauma and nontrauma ED patients are specific entities with regard to age influence. In both groups, increasing age was correlated with higher LOS, higher admission rates and lower ESI classifications. These findings are consistent with the recent literature, according to which the need for medical resources increases with age in both trauma and nontrauma collectives [13]. Interdisciplinary approaches in geriatric trauma care (orthogeriatrics) seem to be advantageous [14]. The simultaneous need for both trauma and nontrauma resources may be especially urgent at the beginning of the treatment course. A team approach including both trauma and geriatric expertise may best fulfill this demanding challenge [12].

\section{Limitations of the Study}

This study has some limitations: data analysis was done retrospectively using anonymous data established in a quality evaluation project. Although the number of patients is high, a one-month study period does not account for seasonal variability. 
Fig. 1. Median ED LOS in nontrauma and trauma patients of different age groups. Error bars: $95 \%$ CI.

Fig. 2. ESI in trauma and nontrauma patients aged $<70$ years and $\geq 70$ years.
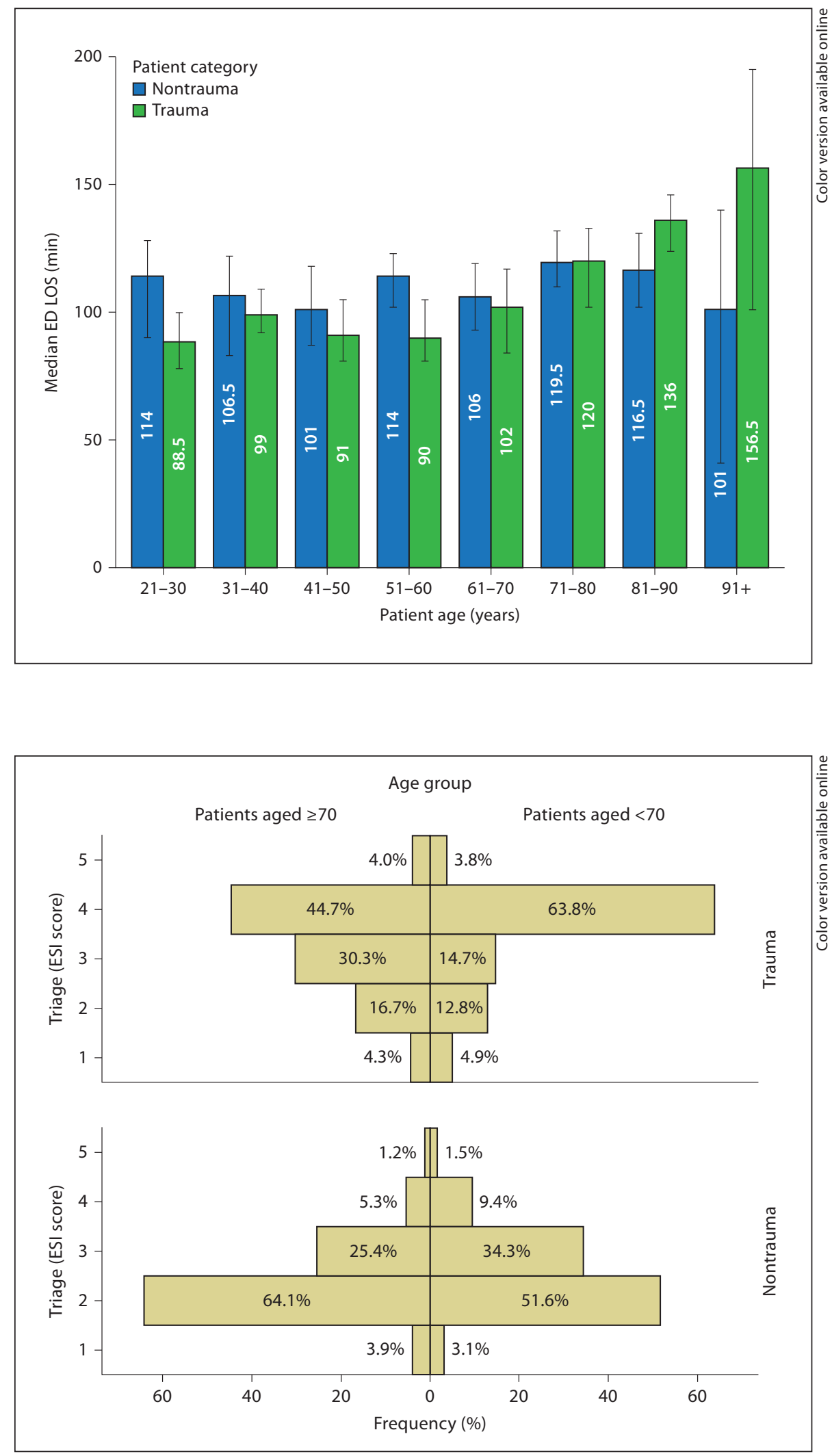
Some parameters, such as patients' comorbidities and interdisciplinary approach are missing. These parameters are known to have an influence on LOS in the ED. However, factors like number and qualification of ED staff and interdisciplinary approach have been kept constant throughout the study period and therefore should not have influenced the impact of age on our results. Comorbidities and patient triage on the other hand may be well correlated with age. Further studies are needed to understand why the correlation of age and ED LOS and admission rate differs between trauma and nontrauma patients. Future investigation should focus on the mechanisms of interaction between age, comorbidities, triage results and the demand of resources in the ED.

\section{Conclusions}

In our study, trauma patients aged $\geq 70$ years displayed a longer LOS in the ED than nontrauma patients, indicating a higher need for ED resources. Admission rates of trauma and nontrauma patients are nearly equally correlated with age whereas the correlation between age and LOS is stronger for trauma patients. This may reflect the increasing level of comorbidity and other geriatric characteristics, which are getting more and more prominent with increasing age. As in orthogeriatrics, an interdisciplinary approach in EDs might be advantageous and should include geriatric expertise.

\section{References}

$>1$ Weyrich P, Christ M, Celebi N, Riessen $\mathrm{R}$ : Triage systems in the emergency department (in German). Med Klin Intensivmed Notfmed 2012;107:67-78.

$\checkmark 2$ Pines JM, et al: International perspectives on emergency department crowding. Acad Emerg Med 2011;18:1358-1370.

3 Gardner RL, Sarkar U, Maselli JH, et al: Factors associated with longer ED lengths of stay. Am J Emerg Med 2007;25:643-650.

-4 Strange GR, Chen EH: Use of emergency departments by elderly patients: a five-year follow-up study. Acad Emerg Med 1998;5:11571162.

$\checkmark 5$ Ciccone A, Allegra JR, Cochrane DG, et al: Age-related differences in diagnoses within the elderly population. Am J Emerg Med $1998 ; 16: 43-48$.
6 Grossmann FF, Zumbrunn T, Frauchiger A, Delport K, Bingisser R, Nickel CH: At risk of undertriage? Testing the performance and accuracy of the Emergency Severity Index in older emergency department patients. Ann Emerg Med 2012;60:317-325.

$\checkmark 7$ Wuerz RC, Milne LW, Eitel DR, Travers D, Gilboy N: Reliability and validity of a new five-level triage instrument. Acad Emerg Med 2000;7:236-242.

$>8$ Koehrmann M, Schellinger PD, Breuer L, Dohrn M, Kuramatsu JB, Blinzler C, Schwab S, Huttner HB: Avoiding in hospital delays and eliminating the three-hour effect in thrombolysis for stroke. Int J Stroke 2011;6: 493-497.

9 Lendemans S, Ruchholtz S: S3 guideline on treatment of polytrauma/severe injuries: trauma room care. Unfallchirurg 2012;115: 14-21.

10 Dellinger RP, Levy MM, Carlet JM, Bion J, Parker MM, Jaeschke R, et al: Surviving Sepsis Campaign: international guidelines for management of severe sepsis and septic shock: 2008. Crit Care Med 2008;36:296327.
1 Atzema CL, Austin PC, Tu JV, Schull MJ: Emergency department triage of acute myocardial infarction patients and the effect on outcomes. Ann Emerg Med 2009;53:736745 .

12 Baum SA, Rubenstein LZ: Old people in the emergency room: age-related differences in emergency department use and care. J Am Geriatr Soc 1987;35:398-404.

13 Carpenter CR, Stern ME: Emergency orthogeriatrics: concepts and therapeutic alternatives. Emerg Med Clin North Am 2010;28: 927-949.

- 14 Friedman SM, Mendelson DA, Bingham KW, Kates SL: Impact of a comanaged Geriatric Fracture Center on short-term hip fracture outcomes. Arch Intern Med. 2009;169: 1712-1717. 